\title{
DESIGNING LINGUISTICALLY FLEXIBLE SCAFFOLDING FOR SUBJECT- SPECIFIC ACADEMIC LITERACY INTERVENTIONS
}

\author{
Adelia Carstens \\ University of Pretoria
}

The majority of South African universities are faced with the challenge of teaching subjectspecific academic literacy in English to linguistically diverse student groups, while the academic literacy lecturers themselves display a variety of first languages and linguistic repertoires. Over the past 50 years, a major consideration in L2 teaching has been whether to focus only on the target language (the L2), or to allow the first languages of the learners into the L2 classroom as linguistic and cognitive resources, while retaining the focus on the target language. This article departs from the premise that the language focus (either multi- or monolingual) is not crucial, but rather how L2 learning is scaffolded. A scaffolding framework is derived from Van Lier's (2004) model and Walqui's (2006) socioculturally embedded strategies for improving the performance of students' learning of subject content in their second language, namely modelling, bridging, building schema, contextualisation, representing text and developing metacognition. In the article, I demonstrate that Walqui's six techniques can be adapted to accommodate monolingual as well as bi-/multilingual dimensions of teaching an L2, and can be justified with reference to Van Lier's four-quadrant model. I conclude that a scaffolding approach to teaching language and content in an integrated way is part of any good language pedagogy. However, scaffolds should ideally be designed within a multisemiotic mindset and aimed at producing lasting cognitive gains.

\section{Keywords}

Academic literacy; language scaffolding; linguistic diversity; L2 teaching strategies; multilingual pedagogy; translanguaging

\section{INTRODUCTION}

In South African higher education, the majority of students who choose English as the preferred medium of instruction are additional language speakers (Haberland, Lønsmann \& Preisler, 2013; Van der Walt, 2013). Similar to, for instance, students at the University of Puerto Rico (Mazak \& Herbas-Donoso, 2014), South African university students display a wide range of English proficiencies: a small minority are mother-tongue speakers of English; some studied English as a subject for 12 years (primarily mother-tongue speakers of Afrikaans); some received tuition from Grade 4 through medium of English (the majority of black South African students taught at public schools in rural and township schools); while a number of second language speakers graduated from private English-medium high schools and are well prepared for university study through medium of English. 
Contrary to the overwhelming support among language educators for a multilingual higher education system (Maseko, 2015; Khumalo, 2015) and government policy documents advocating the development of South Africa's African languages as scientific languages (Department of Education, 2002, 2003; Department of Higher Education and Training, 2013), universities are becoming more and more monolingual. One of the reasons is the preference of the majority of students to study through medium of English.

A particular challenge associated with university language policies that adopt English as the only language of teaching, learning and assessment, is facilitating the acquisition of subjectspecific academic literacy in English in linguistically diverse classes, while academic literacy lecturers themselves display a variety of linguistic repertoires. Amidst the world-wide trend to embrace multilingualism, an important consideration is whether to allow only the target language (English in the South African context) in the academic literacy classroom, or to create space for students to draw on their L1's or strongest languages as social, linguistic and cognitive resources.

This article departs from the premise that the focus in the teaching of English for specific academic purposes (either multi- or monolingual) is not crucial, but rather how L2 learning is scaffolded. The framework that forms the basis of the discussion comprise a set of socioculturally embedded strategies proposed by Walqui (2006) for improving the performance of students' learning of subject content in their second language. These are modelling, bridging, building schema, contextualisation, re-presenting text and developing metacognition. In the article, I demonstrate that Walqui's framework is not only versatile in allowing adaptation of the six techniques to accommodate monolingual as well as bi-/multilingual foci, but also in allowing space for distributing agency among lecturers, peers and individual students.

First, an overview is given of approaches to language pedagogy with a monolingual focus, and approaches with a bi-/multilingual focus. Thereafter, the notion of scaffolding is unpacked, with specific emphasis on Van Lier's (2004) model, followed by a discussion of Walqui's (2006) six scaffolding strategies, and how they can be adapted to accommodate the linguistic repertoires of students and lecturers in linguistically diverse academic literacy classes with a subject-specific focus.

\section{OVERVIEW OF APPROACHES TO L2 TEACHING}

For the past 50 years, the pendulum in language teaching methodologies has been shifting back and forth between purely monolingual L2 approaches and approaches that accommodate the L1 in the classroom, with additional variation introduced by a dual focus on content and language instruction. Monolingual approaches maintain that the target language should be the only medium of instruction and communication used in the classroom. The rationale is that, the more students are exposed to the target language, the greater the possibility of internalisation, and the sooner they will start thinking in that language. Paradigms in language teaching that adhere to a monolingual approach, with a focus on the target language, include the Direct Method, the Audio-lingual Method, the Natural Approach, the Total Physical Response and Communicative Language Teaching. More recent versions of Communicative Language Teaching have become more tolerant of the use of students' first languages in the classroom, for example Content-based Instruction and Task-based Instruction (LarsenFreeman \& Anderson, 2011: 157). Similar to Content-based Instruction, Content and Language Integrated Learning (CLIL) is also focused on learning a second or a foreign language while 
mastering subject content (Coyle, 2007: 545), but although code-switching between the mother tongue and the target language seem to be important mechanisms in CLIL, they have not yet been explored in the research literature (Coyle, 2007: 558).

Bi- and multilingual approaches depart from the premise that there is no compelling reason why the L1 should not be used in the L2 classroom. Part of the rationale is that languages do not operate separately in learners' minds, and that use of the L1 is a normal process that facilitates L2 production and supports learning in another language cognitively, emotionally and socially (Brooks \& Donato, 1994: 268; Cummins, 2007: 231). One of the most welldocumented methods that overtly brings the L1 into the L2 classroom is the Grammartranslation method. However, due to its strong emphasis on a-contextual, rule-based learning in a lecturer-centred classroom, this method has fallen into disrepute. Community Language Learning can also be regarded as a bilingual approach, in that the L1 is the initiator of meaning (Cook, 2001; Larsen-Freeman \& Anderson, 2011: 86). The New Concurrent Method (Faltis, 1990), which is a relatively new teaching method, advocates a balance between using the L1 and the L2 in the classroom: the lecturer switches from one language to the other at key points in accordance with particular rules. More recently, 'critical' multilingual pedagogies, such as translanguaging, have been gaining ground. Translanguaging is a 'planned and systematic use of two languages for teaching and learning inside the same lesson' (Lewis, Jones \& Baker, 2012: 643) to facilitate understanding, L2 learning, and L1 development. However, Carstens (2015b) contends that translanguaging strategies for academic literacy teaching at university level have not been investigated in a systematic way, and suggests that curriculum guidelines should first be developed and then operationalised as module-specific exercises for use in classrooms and tutorial groups. The present article follows up on this suggestion by exploring possible strategies to scaffold L2 learning by creating space for utilising students' strongest languages in the learning process.

\section{THE NOTION OF SCAFFOLDING}

The notion of scaffolding has its roots in Sociocultural Theory (Vygotsky, 1978), as expanded by, among others, Bakhtin (1981). A central tenet is that language is the main vehicle of thought and starts as dialogue and social interaction, which in turn facilitates learning and development. All learning is co-constructed through processes of apprenticeship and internalisation, and thus skills and knowledge are transformed from the social to the cognitive. The Vygotskyan Zone of Proximal Development, which is a central construct in Sociocultural Theory, refers to the distance between independent problem-solving and potential development under adult guidance or in collaboration with more competent peers.

The concept of scaffolding became prominent in the work of Bruner (1983: 163), who defined it as a process of creating space for facilitating access to the learner, and then gradually removing support as the learner becomes skilled enough to manage the task independently. A similar approach is held by Donato (1994: 40). Cotterall and Cohen (2003: 159) emphasise the role of scaffolding in fostering autonomy. Gibbons (2003) moves beyond a view of scaffolding as a vehicle to promote autonomy by asserting that scaffolding does not necessarily always follow the direction from top to bottom, where the top of the scale is represented by curriculum design; the middle comprises certain activities that instantiate the curriculum; and the bottom provides moment-to-moment support through a process of collaborative interaction. As students become more proficient and take control of their own learning the scaffolds at the top 
may be altered, transformed or completely dismantled. This perspective of scaffolding is represented by Figure 1:

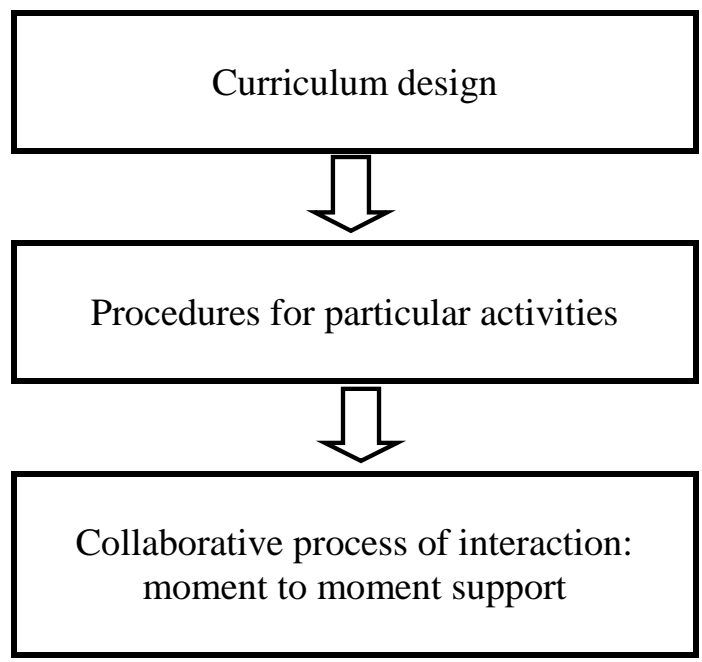

\section{Figure 1: Schematic representation of Gibbons' (2003) view of a scaffolding hierarchy}

In discipline-specific academic literacy modules, the overt aim is to design curricula with concrete outcomes serving as top-level scaffolds. For instance, in a module taught to students of Construction Economics, one of the primary module outcomes is 'demonstrating the competency to document a visit to a construction site by integrating primary and secondary research in the format of a logically structured, stylistically appropriate, well-written, technically correct and visually appealing report.' At the second level, this outcome is scaffolded by themes that instantiate a genre-process approach, and at the lowest level classroom materials and tasks introduce scaffolding that are aimed at improving the ability to write well-formed sentences and use the appropriate register. Apart from the curriculum, there is also the situational context of the classroom, where the lecturer needs to make decisions on instructional scaffolding, for instance whether the L1 should be used selectively.

Van Lier (2004) moves away from a linear model, and highlights how shifts in agency may occur during the process of scaffolding, as represented by the four-quadrant model in Figure 2:

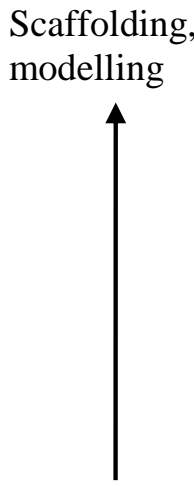

Resourcefulness, self-access

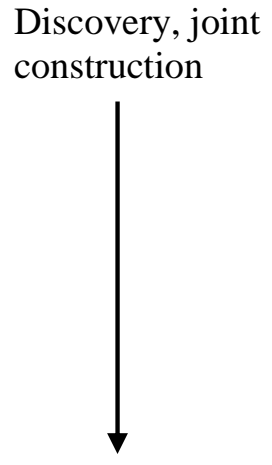

Learning by teaching

Figure 2: Schematic representation of Van Lier's scaffolding model 
The top left quadrant (1) represents the canonical understanding of scaffolding, namely, support by more experienced peers or teachers using scaffolds such as textual models; the top right quadrant (2) represents support by equals, which is typically collaborative; the bottom right quadrant (3) focuses on a less prototypical understanding of scaffolding, namely that more experienced peers may achieve learning gains though explaining difficult concepts to less advanced peers; and the bottom left quadrant (4) represents the individual's internalisation of scaffolding, which entails the development of cognitive and meta-cognitive structures that facilitate learner autonomy.

The next section discusses Walqui's (2006) scaffolding strategies, with reference to how they can be linked to Van Lier's model, and with indications of how they may be customised for use in linguistically complex academic literacy classrooms.

\section{SCAFFOLDING STRATEGIES}

Walqui (2006) proposes six types of scaffolding that are of particular importance in improving the performance of students' learning of subject content in their second language: modelling, bridging, building schema, contextualisation, re-presenting text and developing metacognition. Although Walqui does not restrict the techniques to classrooms with a monolingual focus, she also does not explicitly refer to the inclusion of the L1 in the scaffolding process. In the discussion below, I demonstrate that Walqui's six techniques are sufficiently flexible to accommodate monolingual as well as multilingual and multimodal foci.

Modelling: Modelling, which is represented in the first quadrant of Van Lier's (2004) model, is a canonical example of scaffolding. Intrinsically, it is a monolingual strategy that involves providing students with good examples of the final product, by, for instance, making available previous students' work (Walqui, 2006: 171) or published texts, or adapting existing texts to display the prototypical characteristics of the genre in question. It is therefore no surprise that genre approaches to teaching English as a second language include modelling as a central element (Cope \& Kalanzis, 1993; Hyland, 2003). Modelling may take place at the level of macro-genres, such as reports, essays and proposals; and micro-genres or text types, such as description, comparison, explanation and analysis. Modelling also plays an important role in CLIL. Llinares, Morton and Whittaker (2012), for instance, devote two book chapters to the role of models in inducting students into the genres, grammar and vocabulary of specific subject fields. As a practical scaffolding exercise, Walqui (2006: 171) recommends providing students with handouts that contain instructional information on how to go about when performing a particular task, while the reverse side may contain examples of phrases and terminology that students may use as they perform tasks related to content and/or language. At this level, bi- or multilingual dimensions can be introduced in the format of glossaries of academic vocabulary and subject-field terms, which tie in with concept of 'register' in genre approaches.

Bridging: This technique has to do with valuing students' prior knowledge and literacies through linking new knowledge to past experience. Confidence is built as students start realising that their everyday knowledge is both valued and desired (Walqui, 2006: 171). Bridging may be accommodated in quadrants 2 and 4 of Van Lier's model, as it comprises both a collaborative component (when students share and discuss their prior knowledge) and an autonomy-building component (when students take stock of the skills and knowledge they have acquired, and reflect how this knowledge can be used as scaffolding to internalise new 
knowledge). Carstens (2015a) illustrates how students' passages from home and school to university can be bridged by writing and sharing their literacy narratives. They are prompted to think about literacy identities as socially constructed, about their roles as advocates of a more equitable society, and about their journey towards becoming legitimate members of a particular discourse community.

In its classical format, literacy narrative pedagogy is a monolingual technique. More recently, however, proponents of translanguaging have emphasised its benefits in fostering multilingualism. Canagarajah (2011) encourages code-meshing (the realisation of translanguaging in texts) in the writing of literacy narratives 'to develop a critical awareness of the choices that are rhetorically more effective' (Canagarajah, 2011: 402).

Another bridging technique mentioned by Walqui (2006: 171) is the provision of anticipatory guides to serve as a classroom activity at the beginning of a new topic. A lecturer requests the class to compile a two-column guide, of which the first contain what students know about the topic, and the second, questions they may have about the topic. In this way students learn that they do possess knowledge that can assist them to predict or infer more than they know. In multilingual classes, students may be encouraged to write down their prior knowledge in the L1 to facilitate conceptualisation.

Translanguaging can be used for peer collaboration in classrooms comprising students who speak a variety of mother tongues. According to Brooks and Donato (1994: 268), the use of the L1 'is a normal psycholinguistic process that facilitates L2 production and allows the students both to initiate and sustain verbal interaction with one another'. For Cook (2001), purposes such as explaining a task to each other, negotiating the roles of group members in collaborative assignments and checking their understanding or production of the L2 through the L1 are examples of such scaffolding. These ideas also resonate with Carstens' (2016) findings on translanguaging in an academic literacy class for students of Construction Economics. The majority of the students were very positive about opportunities to use the L1 in making sense of complex subject-field concepts and collaborating in assignments.

Building schema: The use of schemas was introduced by British psychologist Frederic Bartlett, and the term 'schema' became popular through the work of Piaget. It was expanded into schema theory by Richard Anderson (Anderson \& Pearson, 1984). Schema theory has assisted literacy researchers in understanding more fully the processes readers and writers use to store and retrieve knowledge and experience. One way of facilitating schema-building is to start a lecture with an advance organiser. A schematic advance organiser can also be presented to students, which they can then use to analyse a text with the assistance of the lecturer (topdown) (Walqui, 2006: 173). This would be an application of a quadrant 1 activity. In multilingual classes, the lecturer can present an advance organiser in more than one language to enable students to use the L1 for triggering declarative or procedural knowledge. Where schemas do not exist because of a lack of knowledge and experience in a particular domain, students can build their own by skimming a text and noting important headings and subheadings, table and figure captions, etc. In this way, a student can build up a preliminary schema and start reading with some sense of familiarity with the topic. This would primarily comprise a quadrant 4 activity.

The use of concept mapping as an organiser of conceptual schemas, also in a second language, has been explored since the 1970s by educationist Joseph Novak and his colleagues (Novak \& 
Cañas, 2009). Concept maps derive from Ausubel's cognitive psychology (Ausubel, 1963), according to which learning takes place when new concepts are assimilated into existing concepts and propositional frameworks in the learner's mind. A concept map comprises concepts (perceived regularities in events or objects), designated by a label in the target language, and relationships between the concepts. According to research by Van Boxtel, Van der Linden, Roelofs and Erkens (2002: 40), concept mapping yielded significant learning effects when used as part of group tasks in a physics class, particularly regarding the quality of student interaction around physics concepts. The impact that multilingual concept maps with definitions in multiple languages may have on simplifying complex concepts was explored by Carstens (2016), but the validity of her findings still has to be proven empirically.

The use of concept maps may feature at all levels of Van Lier's model: understanding a new concept can be scaffolded using information visualisation plus text to name concepts and relationships between them (quadrant 1); students can be given a collaborative task to plot the relationships between a linear list of terms to show that they understand the interrelationships between components within a complex concept (quadrant 2); also in small groups students who have already grasped a concept may use translanguaging to explain it to other members of the group who share the same mother tongue, while other members translate the explanation in English (quadrant 3); individual students may use monolingual or multilingual concept mapping as a tool for understanding and memorising content.

Contextualisation: This scaffolding technique is important because academic language is in essence decontextualised (Cummins \& Swain, 1986), unlike everyday language which occurs in face-to-face situations where verbal cues are available for interpretation and disambiguation. One of the greatest challenges facing university students is the reading of scholarly publications, such as research articles, in the L2. The language is dense and arguments are structured in a linear way. As a monolingual scaffolding strategy, Walqui (2006: 173) suggests that lecturers should embed context-independent academic language in a sensory context. This includes not only metaphors and analogies, but also pictures, film and authentic objects to bring complex ideas closer to the students' real-world experience. In utilising multimodal resources lecturers may call upon students' multiple literacies to disambiguate and simplify complex concepts. Students' own (re-)construction of meaning by means of pictures, music, film, 3D objects, etc., may further enhance the learning process, which is a confirmation that scaffolding can operate from the bottom up. Contextualisation can feature in all four quadrants of Van Lier's model.

Re-presenting text: As a monolingual strategy, re-presenting text is the process and product of 'translating' a text into another text type with a different purpose, style, language or structure. It is a technique that is useful for learning about audience, and entails the transformation of vocabulary and linguistic constructions from one genre to another. An eyewitness account of an event can, for instance, be transformed into a formal incident report; instructions can be transformed into a description. For students, this kind of task-based language learning, which is typically operationalised as a quadrant 1 activity type, is meaningful and interesting because the emphasis is placed on the communication that is being carried out rather than on its formal aspects (Walqui, 2006: 175).

Re-presenting the same text in another language, which may be regarded as the bilingual equivalent of paraphrasing, is known as translation. According to Zoijer (2009: 32), the Grammar-translation Method was the single most important factor in discrediting translation 
as a language teaching tool. However, many students who study through medium of an L2 use translation as a mental activity when reading or writing in the L2. Cook (2001) points out that translation is not necessarily an activity of converting chunks of one language into chunks of the other. She concludes that 'if the L1 and the L2 co-exist in the same mind, both languages can be used at the same time'.

Zoijer (2009) provides an elaborate exposition of the arguments that have been levelled against translation in the literature, with plausible refutations. The most important arguments in favour of the use of translation as a language teaching strategy include the following: translation promotes students' ability to expand their range of expressions as it counters avoidance strategies; translation is the most efficient way of explaining new vocabulary and thus encourages the student to expand his/her range of expression; translation is an efficient assessment tool for comprehension on the textual, syntactic and semantic level; and translation assists the learner to slowly build up a reflective language consciousness about the functions of language. Pellatt (2009: 345) adds the potential of translation to facilitate schema-building by providing the reader with a means to write down, word by word, sentence by sentence, a description of his or her schema of the source text, which then becomes a concrete written record of the reader's thought processes.

A translation strategy that may fulfil an important scaffolding purpose in classrooms with a focus on content and language learning is the use of bilingual dictionaries and glossaries particularly if definitions and usage examples are given in both the L1 and the L2. Schmitt (1997) found that $85 \%$ of students find the consultation of bi- or multilingual glossaries useful, amongst others to draw on their strongest languages for the conceptualisation of complex concepts, and to remember and broaden lexical knowledge in both the L1 and the L2.

Velasco (n.d.) refers to the process of changing a representation from one semiotic mode to another as 'intersemiotic translation', whereas Suhor (1984) uses the term 'transmediation'. Transmediation may, for instance, refer to turning a verbal text into a visual text such as a table or a graph, or describing the numerical text in a table or on a graph in verbal text. Transmediation has recently been recognised as a form of translanguaging, as it opens up spaces for multimodal communication as part of the multimodal advantages of translanguaging by allowing multilingual speakers to make context-sensitive and strategic choices from all the semiotic resources they have at their disposal (Wei, 2011: 1).

Developing metacognition: Metacognitive scaffolding may involve quadrants 1 to 3, but is ultimately aimed at developing quadrant 4 skills. Metacognitive skills include knowledge and awareness of available strategies, and the ability to choose the most effective one; conscious application of strategies; monitoring, evaluating and adjusting performance during an activity; and planning for future performance based on the evaluation of past performance.

Metacognitive strategies typically focus on a particular target language, as in the method known as Reciprocal Teaching (Brown \& Palincsar, 1985). Brown and Palinscar's research focused on the strategies expert readers use when reading a complex text. They reduced these to the following pedagogical strategies: read, summarise and ask questions. Another (monolingual) example of calling upon metacognitive awareness is to practise self-assessment activities with rubrics. Effective rubrics provide clear criteria according to which students will know which elements of their performance are important and what their next steps should be to enhance the quality of their performance (Ferris \& Hedgcock, 2013: 207). 
Although quantitative studies that investigated the metacognitive benefits of reverting to the L1 during L2 writing have produced conflicting results (Van Weijen, Van den Bergh, Rijlaarsdam \& Sanders, 2009), proponents of the pedagogy of translanguaging have claimed improved metacognitive awareness as a result of using the L1 as a resource (Levine, 2011: 3). Garcia (2011: 147) asserts that translanguaging is an essential metadiscursive tool for students of the twenty-first century, while Adamson and Fujimoto-Adamson (2012: 64) claim that if students are allowed to choose how and when to switch languages, 'they assume an empowering self-managing role of their own language acquisition and reflect upon those choices [...] which, in terms of self-access use is a metacognitive skill essential in autonomous learning'. Metacognition can thus be facilitated through monolingual scaffolding techniques as well as through creating space for translanguaging in multilingual contexts.

\section{CONCLUSION}

Linguistically complex teaching situations demand creative support (scaffolding) strategies. It is useful to think of scaffolds (the tools used in the scaffolding process) as a set of semiotically flexible sociocultural strategies with lasting cognitive gains, while the process of scaffolding involves introducing, using and removing the scaffolds at appropriate stages to allow students to become legitimate and autonomous members of their discourse communities. Scaffolding should introduce both 'message abundancy' (Gibbons 2003) and message redundancy by redistributing content, emphasising conceptual elements and highlighting linguistic features differently from the way it is done in mainstream modules. If academic literacy lecturers understand the purposes of scaffolding, are aware of its dimensions, and utilise the available scaffolding strategies in their particular teaching and learning contexts, all English L2 students may gain as much academic profit from the mainstream subject matter as their English L1 counterparts.

\section{REFERENCES}

ADAMSON, J \& N FUJIMOTO-ADAMSON. 2012. Translanguaging in self-access language advising: Informing language policy. Studies in Self-Access Learning Journal, 3(1):5973.

ANDERSON, RC \& D PEARSON. 1984. Reading comprehension a schema-theoretic view of basic processes. Technical Report No. 306. Illinois, University of Illinois at UrbanaChampaign.

ASHER, J. 1996. Learning another language through actions (5th ed.). Los Gatos: Sky Oaks Productions.

AUSUBEL, DP. 1963. The psychology of meaningful verbal learning. New York: Grune and Stratton.

BAKHTIN, M. 1981. The dialogical imagination. Austin: University of Texas Press.

BROOKS, FB \& R DONATO. 1994. Vygotskyan approaches to understanding foreign language discourse during communicative tasks. Hispania, 77:262-274.

BROWN, A \& A PALINCSAR. 1985. Reciprocal teaching of comprehension strategies: A natural history of one program for enhancing learning. Technical Report No. 334. Illinois: University of Illinois at Urbana-Champaign.

BRUNER, J. 1983. Child's talk. New York, Norton.

CANAGARAJAH, S. 2011. Codemeshing in academic writing: Identifying teachable strategies in translanguaging. The Modern Language Journal, 95(3):401-417. 
CARSTENS, A. 2015a. Harmonising differences among ethno-linguistically diverse students through literacy narrative pedagogy. International Journal of the Sociology of Language (IJSL), 234:93-114.

CARSTENS, A. 2015b. Developing a multilingual mindset: Promoting the development and use of students' strongest languages and empowering them in English as the academic lingua franca. Inaugural address, University of Pretoria. 10 September. Available from http://repository.up.ac.za/bitstream/handle/2263/50087/Casterns_Developing_2015.pdf [Accessed 8 August 2016].

CARSTENS, A. 2016. Translanguaging as a vehicle for L2 acquisition and L1 development: students' perceptions. Language Matters, 47(2):55-74.

COOK, V. 2001. Using the first language in the classroom. Canadian Modern Language Review, 57(3):1710-1131.

COYLE, D. 2007. Content and language integrated learning: Towards a connected research agenda for CLIL pedagogies. The International Journal of Bilingual Education and Bilingualism, 10(5):543-562.

COPE, B \& M KALANTZIS. 1993. Powers of literacy: A genre approach to teaching writing. London: Falmer Press.

COTTERALL, S \& R COHEN. 2003. Scaffolding for second language writers: Producing an academic essay. ELT Journal, 57(2):158-166.

CUMMINS, J. 2007. Rethinking monolingual instructional strategies. Canadian Journal of Applied Linguistics, 10(2):221-240.

CUMMINS, J \& M SWAIN. 1986. Bilingual education: Aspects of theory, research and practice. London: Longman.

DEPARTMENT OF EDUCATION. 2002. Language policy for higher education. Pretoria: Government Printers.

DEPARTMENT OF EDUCATION. 2003. The development of indigenous languages as mediums of instruction in higher education. Pretoria: Government Printers.

DEPARTMENT OF HIGHER EDUCATION AND TRAINING. 2013. White Paper for Postschool education. Pretoria: Government Printers.

DONATO, R. 1994. Collective scaffolding in second language learning. In Lantolf, JP \& G Appel (Eds.). Vygotskyan approaches to second language research. Norwood, NJ: Ablex Publishing. 33-56.

FALTIS, C. 1990. New directions in bilingual research design. In Jakobson, R \& C Faltis (Eds.). Distribution issues in bilingual schooling. Clevedon: Multilingual Matters. 4557.

FERRIS, DR \& J HEDGCOCK. 2013. Teaching L2 composition: Purpose, process, and practice (3rd ed.). New York: Routledge.

GARCIA, O. 2011. Educating New York's bilingual children: Constructing a future from the past. International Journal of Bilingual Education and Bilingualism,14:133-153.

GIBBONS, P. 2003. Scaffolding language, scaffolding learning. Portsmouth: Heinemann.

HABERLAND, H, D LØNSMANN \& B PREISLER. 2013. Language alternation, language choice and language encounter in international tertiary education. Dordrecht: Springer Science \& Business Media.

HYLAND, K. 2003. Second language writing. Cambridge: Cambridge University Press.

KHUMALO, L. 2015. Intellectualisation of indigenous African languages in South African Higher Education. Keynote address delivered at the National Conference on Multilingualism in Higher Education. Pretoria: Unisa, August 22.

LARSEN-FREEMAN, D \& M ANDERSON. 2011. Techniques \& principles in language teaching. Oxford: Oxford University Press. 
LEVINE, GS. 2011. Code choice in the language classroom. Bristol: Multilingual Matters.

LLINARES, A, T MORTON \& R WHITTAKER. 2012. The roles of language in CLIL. Cambridge: Cambridge University Press.

LEWIS, G, B JONES \& C BAKER. 2012. Translanguaging: origins and development from school to street and beyond. Educational Research and Evaluation, 18(7):641-654.

MASEKO, P. 2015. Reflecting on multilingual teaching and learning practices in SA Higher Education: the case of Rhodes University. Paper delivered at a public discussion forum on institutional language policy and planning issues, Bloemfontein, University of the Free State, August 31.

MAZAK, CM \& C HERBAS-DONOSO. 2014. Translanguaging practices at a bilingual university: A case study of a science classroom. International Journal of Bilingual Education and Bilingualism. Available from http://dxdoi.org/10.1080.13670050.2014.939138 [Accessed: 27 December 2015].

NOVAK, JD \& AJ CAÑAS. 2009. The theory underlying concept maps and how to construct and use them. Available from http://cmap.ihmc.us/publications/researchpapers/theorycmaps/theoryunderlyingconcept maps.htm [Accessed: 25 January 2016].

PELLATT, V. 2009. Translation as a reading comprehension test: Schemata and the role of the 'write it down protocol'. In A Witte, T Harden \& AR de Oliveira Harden (Eds), Translation in second language learning and teaching. Bern: Peter Lang, 243-357.

SCHMITT, N. 1997. Vocabulary learning strategies. In N Schmitt \& M McCarthy (Eds), Vocabulary: Description, acquisition and pedagogy. Cambridge: Cambridge University Press, 199-228.

SUHOR, C. 1984. Towards a semiotics-based curriculum. Journal of Curriculum Studies, 16:247-257.

VAN BOXTEL, C, J VAN DER LINDEN, E ROELOFS \& G ERKENS. 2002. Collaborative concept mapping: Provoking and supporting meaningful discourse. Theory into Practice, 41(1):40-46.

VAN DER WALT, C. 2013. Multilingual higher education. Beyond English medium orientations. Bristol: Multilingual Matters.

VAN LIER, L. 2004. The ecology and semiotics of language learning. Dordrecht: Kluwer Academic.

VAN WEIJEN, D, H VAN DEN BERGH, G RIJLAARSDAM \& T SANDERS. 2009. L1 use during L2 writing: An empirical study of a complex phenomenon. Journal of Second Language Writing, 18:235-250.

VELASCO, JAP. n.d. To see or not to see: Concept visualization in terminological knowledge bases. Available from ceur-ws.org/Vol-578/paper9.pdf [Accessed: 25 January 2016]

VYGOTSKY, LS 1978. Mind in Society. Cambridge, MA: Harvard University Press.

WALQUI, A. 2006. Scaffolding instruction for English language students: A conceptual framework. The International Journal of Bilingual Education and Bilingualism, 9(2):159-180.

WEI, L. 2011. Moment analysis and translanguaging space: Discursive construction of identities by multilingual Chinese youth in Britain. Journal of Pragmatics, 43:12221235.

ZOIJER, H. 2009. The methodological potential of translation in second language acquisition: Re-evaluating translation as a teaching tool. In Witte, A, T Harden \& AR de Oliveira Harden (Eds.). Translation in second language learning and teaching. Bern: Peter Lang. 31-51. 


\section{BIOGRAPHICAL NOTE}

Adelia Carstens is Director of the Unit for Academic Literacy, University of Pretoria. She holds doctorates from Unisa and the University of Pretoria. Prof Carstens has published more than 50 papers in accredited publications and is NRF rated. Her current research interests include multimodality and multilingualism in academic literacy teaching. 